\title{
Um tição de aroeira em contexto arqueológico: contribuição antracológica para a compreensão da relação entre o homem e o ambiente
}

\author{
Caroline Bachelet* \\ Agueda Vilhena Vialou** \\ Gregorio Ceccantini ** * \\ Denis Vialou **
}

BACHELET, C.; VIALOU, A.V.; CECCANTINI, G.; VIALOU, D. Um tição de aroeira em contexto arqueológico: contribuição antracológica para a compreensão da relação entre o homem e o ambiente. R. Museu Arq. Etn., São Paulo, n. 21, p. 115-127, 2011.

Resumo: A antracologia fornece diferentes informações sobre a utilização de recursos vegetais pelas populações pré-históricas do Holoceno seja na dieta alimentar ou no uso da matéria prima como combustível, para as atividades cotidianas (luz, cozinha, calor). Um tição carbonizado, resto vegetal raramente encontrado, foi descoberto em sedimentos arqueológicos datados de $2820 \pm 30$ anos AP (2914 \pm 40 anos cal. AP) associado aos vestígios materiais dos primeiros povos ceramistas da região do Mato Grosso, no abrigo rupestre Ferraz Egreja (Rondonópolis, Mato Grosso). A análise antracológica do tição permitiu a identificação da aroeira. A abordagem ecológica e paleobotânica desse resultado permitiu discutir sobre a identificação desta amostra e sobre o uso, a seleção e o lugar de coleta deste recurso vegetal pelos grupos humanos.

Palavras-chave: Antracologia - Arqueologia - Paleobotânica - Madeira Aroeira.

Introdução

antracologia é o estudo dos macro-restos vegetais carbonizados, provenientes de contextos arqueológicos e fornece informa-

(*) Departamento de Pré-história, UMR 7194, Museu Nacional de História Natural/Instituto de Paleontologia Humana, Paris. Departamento de Botânica, Instituto de Biociências, Universidade de São Paulo. <bachelet@mnhn.fr>

$\left.{ }^{* *}\right)$ Departamento de Pré-História, UMR 7194, Museu Nacional ções sobre o ambiente e as atividades cotidianas das populações do passado (Chabal 1997).

Segundo a natureza do registro estudado, a antracologia pode trazer informações de diferentes aspectos do passado. Primeiramente, os carvões

de História Natural/Instituto de Paleontologia Humana, Paris. A.V.Vialou<avialou@mnhn.fr>; D. Vialou<dvialou@mnhn.fr> (***) Departamento de Botânica, Instituto de Biociências, Universidade de São Paulo-USP.< gregorio@usp.br> 
Um tição de aroeira em contexto arqueológico: contribuição antracológica para a compreensão da relação entre o homem e o ambiente.

R. Museu Arq. Etn., São Paulo, n. 21, p. 115-127, 2011.

podem oferecer indicações paleoecológicas que permitem a reconstrução da paleoflora, da paleovegetação, e por dedução do paleoclima, e a reconstitução do ambiente onde viveram as populações pré-históricas. A antracologia pode trazer, igualmente, dados paleoetnológicos importantes para a compreensão da utilização dos recursos vegetais pelas populações locais (Chabal 1997, Chabal et al. 1999; Sheel-Ybert 1998, 2004; Figueiral 2000).

Os carvões encontrados concentrados em estruturas de combustão são geralmente o resultado da(s) última(s) utilização(ões) de uma fogueira. Desse modo, o carvão associado às concentrações de fogueiras pode fornecer informações sobre a vegetação mais pontuais que os carvões dispersos que, geralmente, são mais abundantes no sedimento (Chabal 1997; Heinz 1990; Badal-Garcia e Heinz 1991). Esses podem resultar do esvaziamento de várias fogueiras, pertencentes a sucessivas ocupações do lugar, e refletir mais a paleovegetação ao longo do tempo (Chabal 1992, 1997; BadalGarcia 1992; Figueiral 1992; Scheel-Ybert et al. 2001).

Paralelamente à identificação taxonômica, o estudo dos restos carbonizados concentrados permite a investigação sobre a utilização da madeira por grupos pré-históricos. Esse tipo de registro se encontra frequentemente associado ao material arqueológico (lítico, cerâmico) e pode indicar uma atividade ou um uso específico da madeira como combustível para iluminação, aquecimento, cozimento de alimentos ou de cerâmica ou mesmo para fins de rituais cerimoniais, por exemplo (Théry-Parisot 2001; Beauclair et al. 2009).

A análise antracológica apresentada neste artigo foi realizada a partir de uma amostra de lenho arqueológico carbonizado associado aos vestígios materiais pertencentes às ocupações pré-históricas do Holoceno recente do sul do estado do Mato Grosso, no Brasil central.

Este artigo se propõe a discutir a identifícação taxonômica do tição buscando compreender suas propriedades e possíveis utilizações. Discutiremos igualmente os conceitos de seleção e coleta da matéria-prima.

\section{Apresentação da área de estudo}

O abrigo rupestre Ferraz Egreja (16³1’033 S; 5449' 653 O) está localizado a cerca de $30 \mathrm{~km}$ da cidade de Rondonópolis, sul do estado de Mato Grosso (Fig. 1). O sítio está inserido em uma reserva particular do patrimônio natural, a RPPN Parque Ecológico João Basso, de propriedade da empresa Agropecuária Jotabasso Ltda.

Essa reserva está inserida numa região dominada pela vegetação de tipo cerrado. Ela se

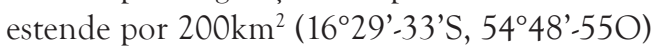
e abriga uma grande diversidade de recursos naturais (fauna, flora, cachoeiras, rios). $\mathrm{O}$ clima atual da região é tropical e caracterizado pela alternância da estação seca (de abril a setembro) e chuvosa (de dezembro a março) (Ribeiro 2008; Coutinho 2002). A vegetação é formada por um mosaico complexo de formações vegetais que vão desde o cerrado às florestas estacionais passando pelos campos (Ratter et al. 2003), o que oferece uma importante diversidade de matérias-primas e produtos alimentares (madeira, frutas, sementes, raízes) (Maroni et al. 2006).

Topograficamente, a reserva é coberta por várias formações rochosas de arenito ruiniformes que sofreram ação da erosão, entre elas a "Cidade de Pedra", uma das mais belas paisagens da reserva natural (Vilhena Vialou et al. 1999). A Cidade de Pedra é constituída de diversos afloramentos rochosos, na forma de torres, que podem estar isolados ou agrupados na paisagem e chegam a medir muitos metros de altura e largura (Vilhena Vialou 2006). Grande parte dessas torres apresenta gravuras e pinturas rupestres e foi usada como abrigos ocasionais ou de longo termo, para populações pré-históricas, durante milênios (Vilhena Vialou 2009). Dos 140 sítios atualmente registrados nessa área, alguns, como Ferraz Egreja, descoberto em 1982, são objeto de escavações arqueológicas (Vilhena Vialou 2009) nos últimos 30 anos, realizadas através de um programa de cooperação científica dirigido pela Dra. Agueda Vilhena Vialou (MNHN-USP) (Vilhena Vialou e Vialou 1994). 


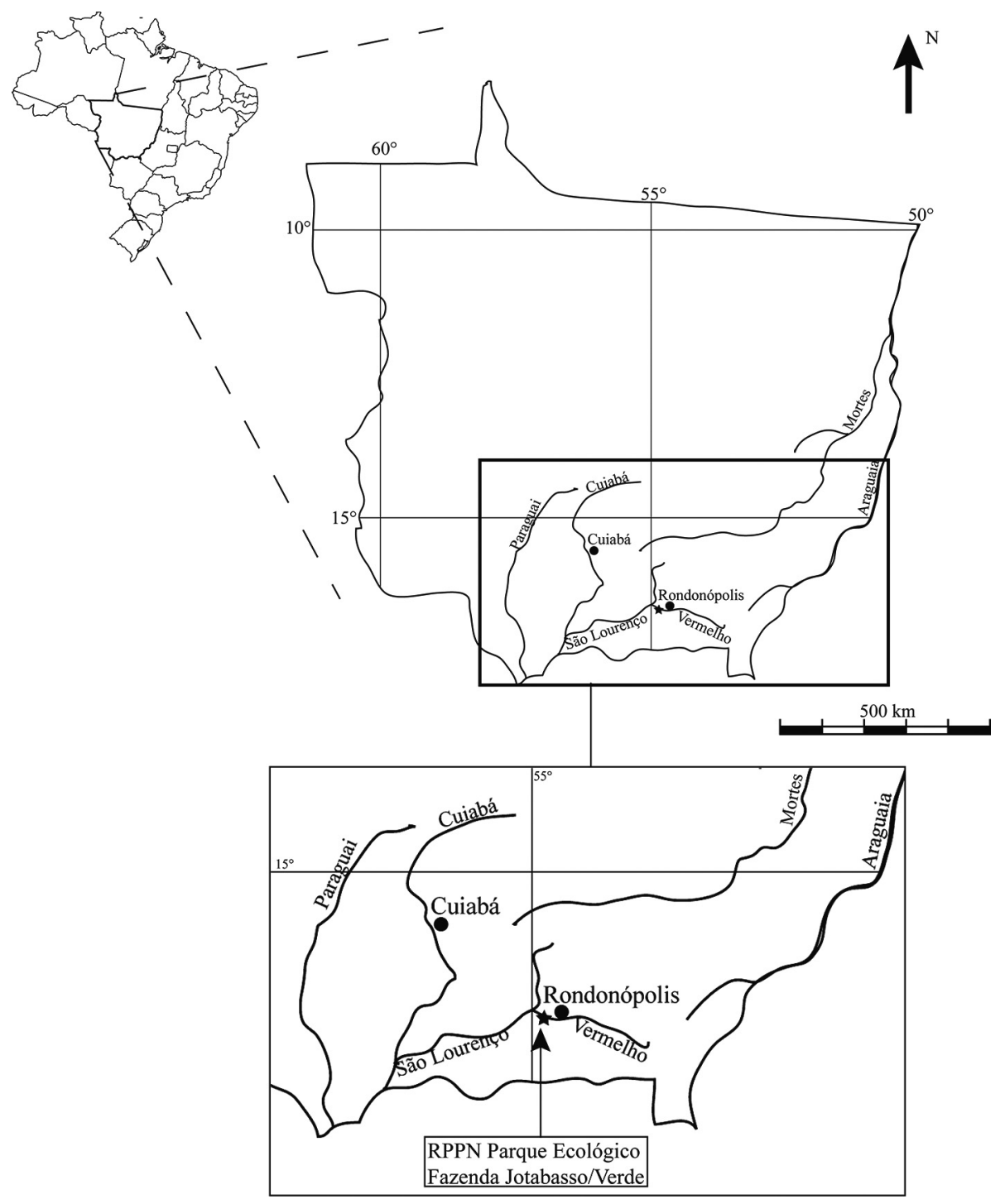

Fig. 1. Área de estudo.

\section{Apresentação do sítio}

O abrigo Ferraz Egreja está localizado na base de uma formação de arenito de forma cilíndrica de aproximadamente $15 \mathrm{~m}$ de diâmetro. $\mathrm{O}$ conjunto, que tem uma forma particular, mais estreito na base que no topo, oferece várias áreas protegidas usadas como abrigo pelas populações (Vilhena Vialou 2006).

Escavações de grandes extensões (cerca de $200 \mathrm{~m}^{2}$ ) realizadas através de métodos, como a decapagem e a micro-decapagem, assim como as diversas sondagens, permitiram a descoberta de uma grande quantidade de vestígios arqueológicos, como a indústria lítica (instrumentos, lascas de arenito, sílex, quartzo), fragmentos cerâmicos e hematitas, que nesse contexto foram utilizadas principalmente como corantes para pinturas rupestres adornando as paredes do abrigo (Vilhena Vialou 2006).

Estruturas de combustão, organizadas ou não, tições, assim como carvões dispersos no sedimento foram encontrados em grandes quantidades. $\mathrm{O}$ conjunto desses vestígios, associados 
Um tição de aroeira em contexto arqueológico: contribuição antracológica para a compreensão da relação entre o homem e o ambiente.

R. Museu Arq. Etn., São Paulo, n. 21, p. 115-127, 2011.

às diversas datações de ${ }^{14} \mathrm{C}$ revelam uma ocupação contínua do sítio que vai desde o Holoceno médio (5.460 \pm 40 anos AP, SACA 17270/

Gif-12428) a períodos mais recentes datados de cerca de 100 anos BP (Vialou et al. 2010).

Devido a sua disposição em torno da base rochosa, o sítio foi dividido em várias áreas de esca- vação (Fig. 2): a área norte (FEI), a área sul (FEII), e a área oeste (FEIII). Apesar de constatarmos que o sítio foi ocupado na sua totalidade, percebemos que a zona sul (FEII) foi objeto de uma ocupação mais importante (Vilhena Vialou 2006).

De fato, o material arqueológico (cerâmica, lítico), as estruturas de combustão e os carvões

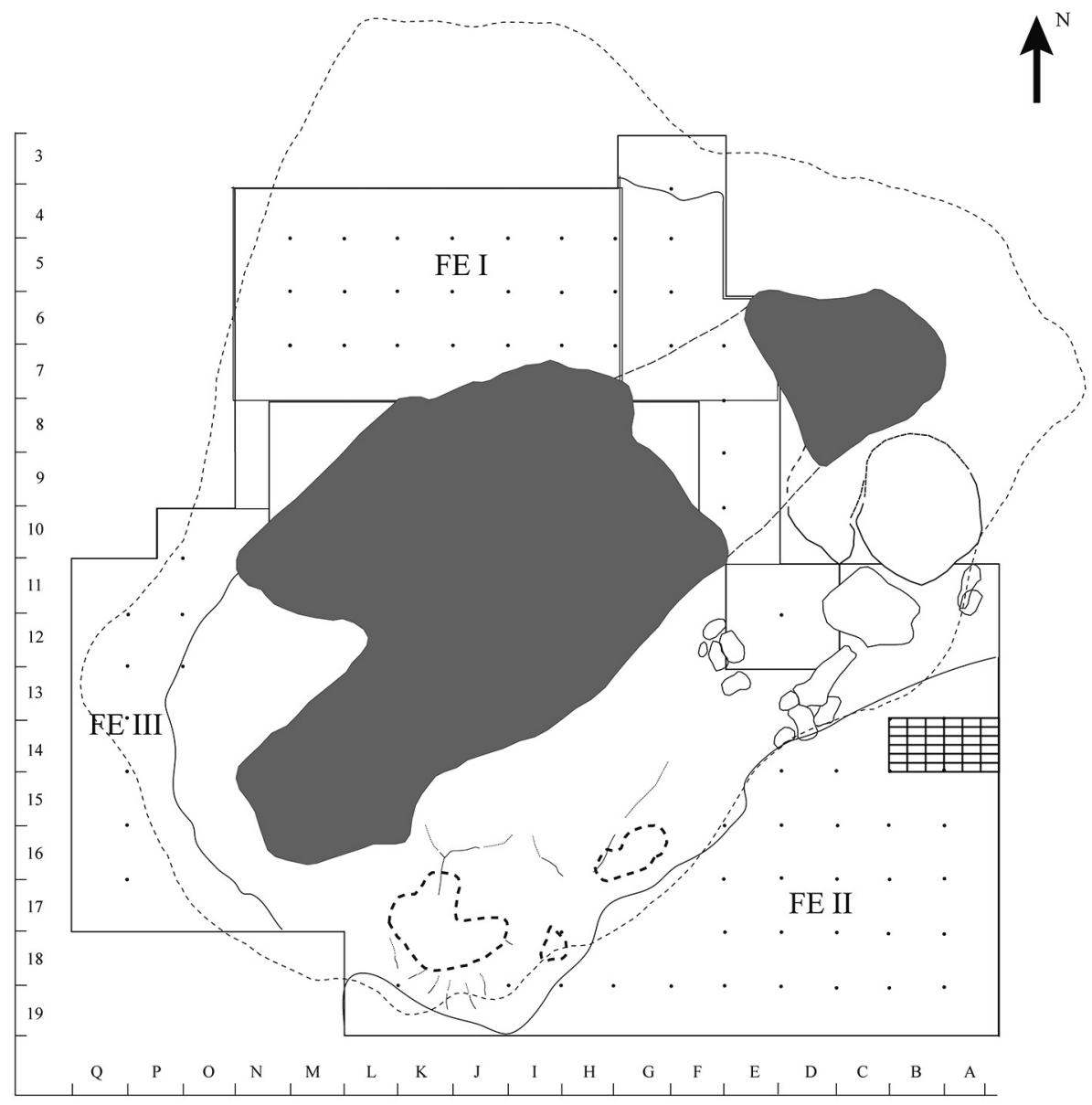

0

Legenda

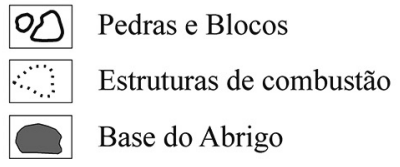

Fig. 2. Plano da área de escavação.

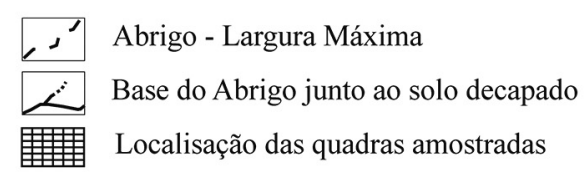

Base do Abrigo junto ao solo decapado

Localisação das quadras amostradas 
se encontram de maneira muito mais abundantes na área FEII, o que indica que atividades mais intensas ocorriam nesta parte do sítio (Vialou et al. 2010). As condições proporcionadas, como sombra, ambiente fresco, e a proximidade de um córrego que se encontra a poucos metros de distância para o leste, poderiam explicar tal exploração maior da área. O material de estudo deste trabalho foi encontrado nessa área sul do abrigo.

\section{Materiais e métodos}

O objeto de estudo deste trabalho é um tição que mede aproximadamente $70 \mathrm{~cm}$ de comprimento, $16 \mathrm{~cm}$ de largura e $10 \mathrm{~cm}$ de espessura e possui a forma de um galho de árvore. Esse tição tinha fragmentos de carvão espalhados por cerca de $10-15 \mathrm{~cm}$ de seu entorno e localizados na quadra $14 \mathrm{AB}$ (Fig. 2). Os vestígios estavam associados a um conjunto de grandes blocos rochosos $(70 \times 15 \times 20 \mathrm{~cm}$ de medida $)$ e de placas de arenito (Fig. 3). É interessante notar que esse tipo de bloco de pedra está presente principalmente nesta parte do sítio e neste nível antigo de ocupação, em especial.

A escavação das quadras permitiu a descoberta de vestígios arqueológicos em associação direta ao tição analisado (Fig. 3), como raros fragmentos de cerâmica e indústria lítica constituída de lascas, estilhas de arenito silicificado, fragmentos de quartzo e de rochas metamórficas chamadas "rochas verdes", uma grande quantidade de fragmentos de minerais de ferro denominada na escavação de hematita (Ferreira e Silva 2005), entre outros vestígios. Um dos fragmentos de cerâmica foi descoberto completamente associado ao tição, permitindo afirmar a sua contemporaneidade. Por conseguinte, a datação do tição de 2820 $\$ 30$ anos AP $(2914 \pm 40$ anos cal.AP) associada ao material arqueológico testemunha as ocupações cerâmicas mais antigas atualmente conhecidas em Ferraz Egreja (Vilhena Vialou 2009).

A fim de determinar se o tição corresponde a um único galho carbonizado ou a uma associação de diversos ramos, amostragens foram
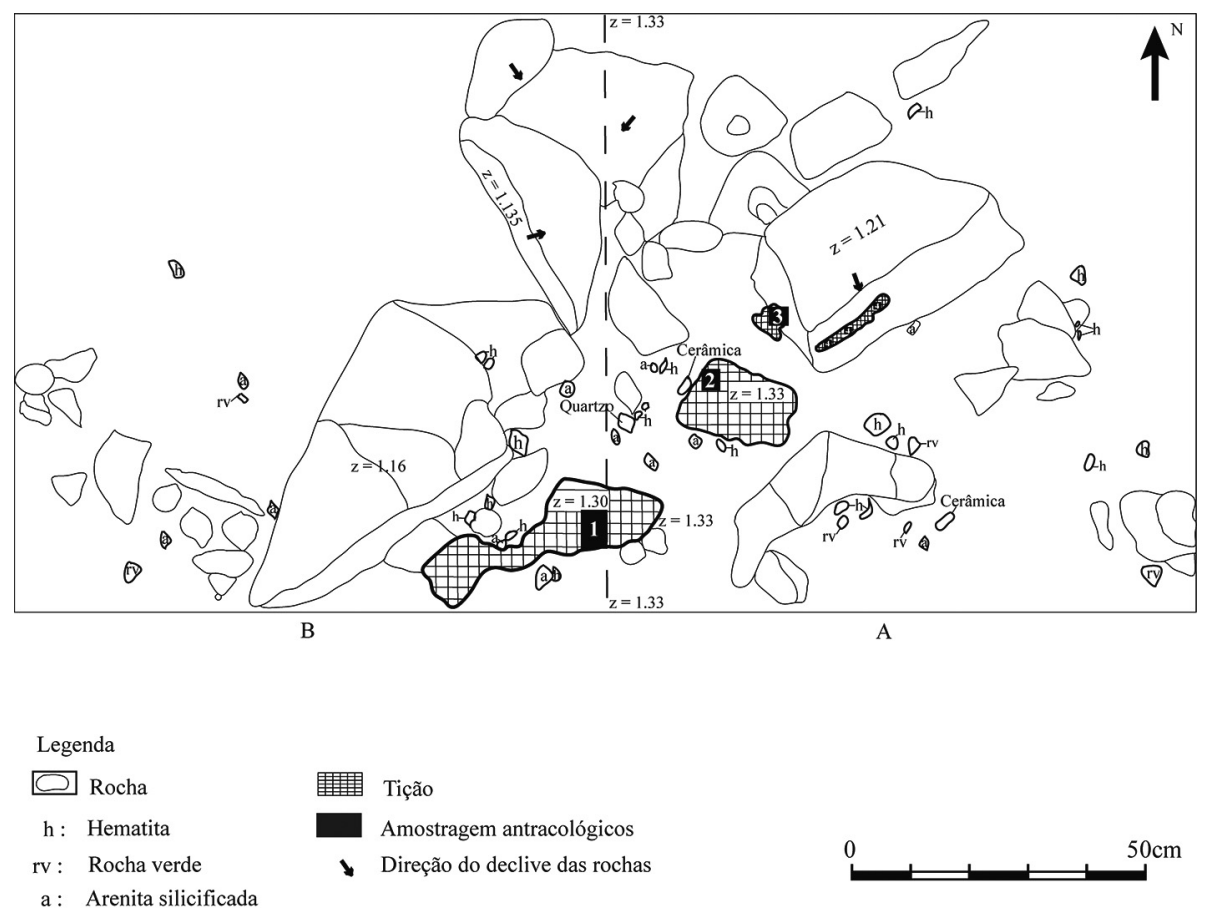

Fig. 3. Esquema 14A-B. 
Um tição de aroeira em contexto arqueológico: contribuição antracológica para a compreensão da relação entre o homem e o ambiente.

R. Museu Arq. Etn., São Paulo, n. 21, p. 115-127, 2011.

realizadas nas quadras $14 \mathrm{~A}$ e $14 \mathrm{~B}$ durante as escavações de 2010 (Fig. 3). Uma parte do tição $(20 \times 12 \times 3 \mathrm{~cm})$ foi coletada para amostra (1) na quadra $14 \mathrm{~B}$, mas o restante não foi coletado, a fim de servir como referência para futuras pesquisas. Na quadra 14A, foram tiradas amostras dos carvões da concentração associada ao fragmento cerâmico (2) e dos carvões contíguos ao bloco de pedra localizado ao norte $(3,4)$. Os fragmentos dispersos, localizados no sul e no sudeste das quadras 14A-B, também foram coletados. Todas as amostras foram peneiradas em água ( $0,4 \mathrm{~mm}$ de malha), secas e triadas em laboratório para depois serem observadas ao microscópio para identificação.

Cem fragmentos de carvões, de dimensão entre $0.4 \mathrm{~mm}$ a $3 \mathrm{~cm}$, foram analisados para determinar se se tratava da mesma madeira. A identificação do carvão vegetal foi realizada em laboratório, utilizando um microscópio de luz refletida, seguindo os métodos tradicionais da antracologia. Cada fragmento de carvão foi fraturado manualmente e observado em três planos: transversal, longitudinal tangencial e longitudinal radial.

Em um segundo momento, a identificação taxonômica foi realizada em comparação com a coleção de referência de madeira carbonizada. Esse referencial foi construído a partir das madeiras modernas recolhidas em todas formações vegetais (cerrado, cerradão, mata semi-decídua) na área da Cidade de Pedra durante sucessivas prospecções pedestres, por G. Ceccantini. Cada árvore que tinha material fértil (folhas, frutos, flores), indispensavèl para a realização da identificação taxonômica por especialistas, foi coletada e inserida na coleção. As madeiras coletadas na Serra das Araras (Ceccantini 2002), área ambiental e arqueologicamente semelhante à área de estudo, localizada a cerca de $200 \mathrm{~km}$ ao norte de Rondonópolis, próximo de Cuiabá, também foram utilizadas para a criação desta coleção de referência antracológica. Essas madeiras foram utilizadas igualmente para criar a coleção de referência de lâminas da Xiloteca SPFW (Instituto de Biociências-USP) (Ceccantini 2002) e para a identificação de carvão arqueológico. No total, a coleção de madeira atual da região de Mato Grosso, e usada para todas as determinações, é composta por 279 indivíduos divididos em 58 famílias e 146 gêneros diferentes pertencentes às diversas formações vegetais do bioma Cerrado. Foram utilizadas a coleção de referência de lâminas da região de Lagoa Santa, Estado de Minas Gerais (Xiloteca SPFW, Instituto de Biociências-USP) (Freire 2011), área coberta pelo bioma cerrado, assim como a coleção de lâminas da Xiloteca Calvino Mainieri do Instituto de Pesquisas Tecnológicas da Universidade de São Paulo.

Paralamente, várias obras e atlas de madeira, mais especializados ou de caráter mais geral, que tratam da anatomia de madeiras do Brasil e América do Sul foram consultados (Détienne e Jacquet 1983; Deschamps 1979, 1980, 1985; Hess 1946, 1948; Fedalto et al. 1989; Mainieri e Chimelo 1989; Record 1942, 1943a, 1943b, 1944a; IAWA 1964, 1989), bem como as listas florísticas da região (Ceccantini 2002 ; Forzza et al. 2010). Foi igualmente utilizado o banco de dados de Insidewood, que reúne muitas descrições e fotografias das madeiras fósseis e atuais de diversas áreas geográficas. A observação e descrição dos diferentes caracteres morfológicos, próprios a cada espécie, foram realizadas para a identificação taxonômica seguindo aproximadamente os critérios definidos pelo IAWA Comittee (1989).

\section{Resultados}

Todos os fragmentos de carvão analisados possuem as mesmas características morfológicas (Fig. 4). Na seção transversal todos os fragmentos possuem anéis de crescimento indistintos ou ausentes, uma porosidade difusa, os vasos em maioria solitários ou múltiplos dispostos em uma linha radial de $2-4$ vasos. Os tilos são muito frequentes e o parênquima axial pode estar indistinto até raramente paratraqueal escasso, dependendo do fragmento. O corte longitudinal tangencial apresenta raios 1-2 seriados e raramente 3 seriados, 4-13 células de altura. Os canais radiais estão raramente presentes, apenas um foi observado. As pontoações intervasculares são alternas e as placas de perfuração, simples. Finalmente, o corte longitudinal radial 
apresenta raios compostos de células procumbentes no centro e linhas de células eretas e/ ou quadradas nas extremidades. As pontoações rádio-vasculares são maiores do que as pontoações intervasculares e fibras são septadas.

Após terem sido observados e descritos, os carvões foram submetidos à comparação com a referência. Os carvões foram identificados como pertencentes à família Anacardiaceae, em especial dos gêneros Myracrodruon sp., Astronium sp. (aroeira, gonçalo-alves, muiaracatiara) e Schinopsis sp. (quebracho, quebracho-colorado) (Fig. 5). Vendo que a separação entre os gêneros não foi possível, eles foram agrupados no mesmo tipo Astronium/Myracrodruon/Schinopsis. As caracteríticas anatômicas das madeiras descritas na literatura (citada acima) parecem confirmar essa identificação.

\section{Discussão}

\section{Identificação}

Segundo a literatura (Détienne e Jacquet 1983; Fedalto et al. 1989; Mainieri e Chimelo 1989; Paula et al. 2007) e as observações rea- lizadas a partir da coleção de referência, essas madeiras possuem características anatômicas muito semelhantes, o que dificulta a separação pela sua anatomia.

Por outro lado, de um ponto de vista botânico, os gêneros Astronium sp. e Myracrodruon sp. são também dois taxons relativamente muito próximos e difíceis de separar. Durante muitos anos, o gênero Myracrodruon sp. foi considerado como um subgênero do gênero Astronium sp. Ele foi reabilitado por Santin (1989) e Santin e Leitão-Filho (1991) após um estudo sobre a revisão taxonômica do gênero Astronium Jacq. Além disso, Schinopsis sp. também possui caracteres botânicos muito próximos a tal ponto que é frequentemente confundido com os outros dois e comercializados como aroeira (Lorenzi 1992).

As determinações taxonômicas de madeira atual, seja a partir de sua anatomia ou da observação botânica, apresentam tantas dificuldades que a criação do mesmo tipo foi mais segura.

\section{Ecologia propriedades e usos}

Os gêneros Astronium sp., Myracrodruon sp. e Schinopsis sp. pertencem à família Anacardiaceae, uma das mais importantes famílias da flora
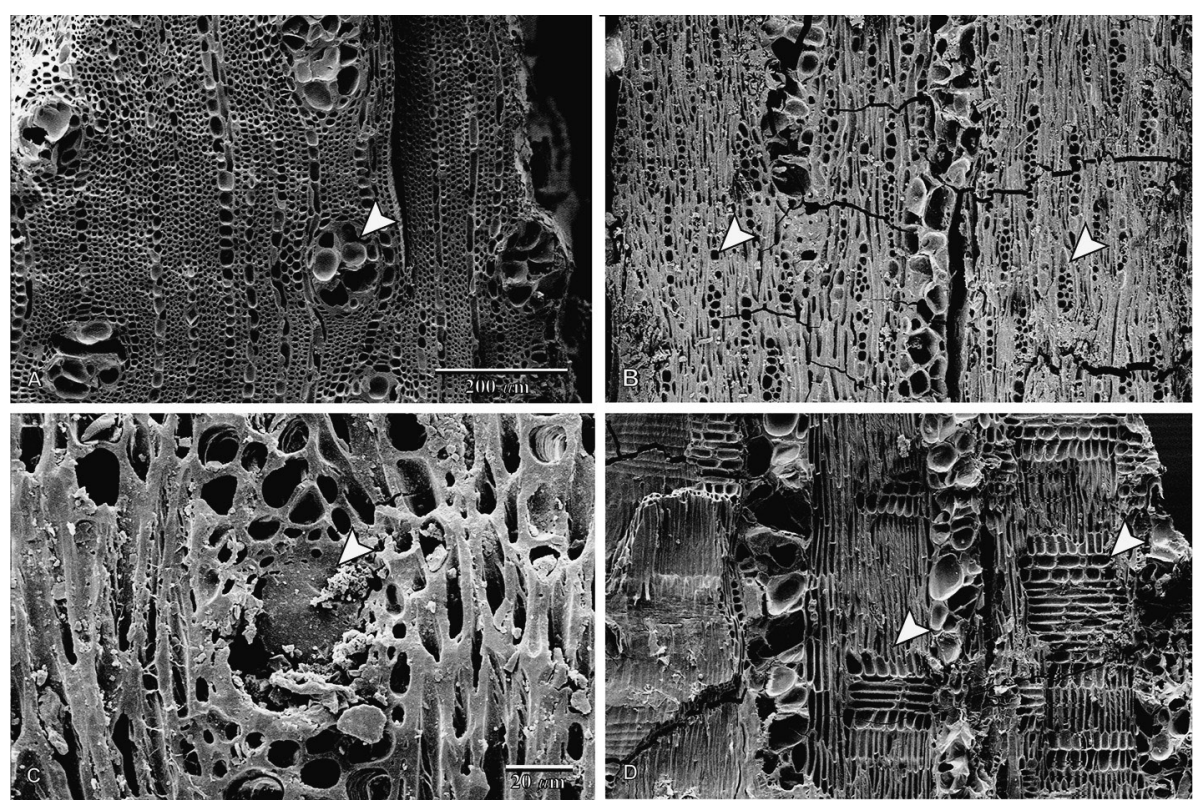

Fig. 4. Tição. Fotografias em microscopia electrônica de varredura. A: Plano transversal. B-C: Plano longitudinal tangencial. D: Plano longitudinal radial. 
Um tição de aroeira em contexto arqueológico: contribuição antracológica para a compreensão da relação entre o homem e o ambiente.

R. Museu Arq. Etn., São Paulo, n. 21, p. 115-127, 2011.
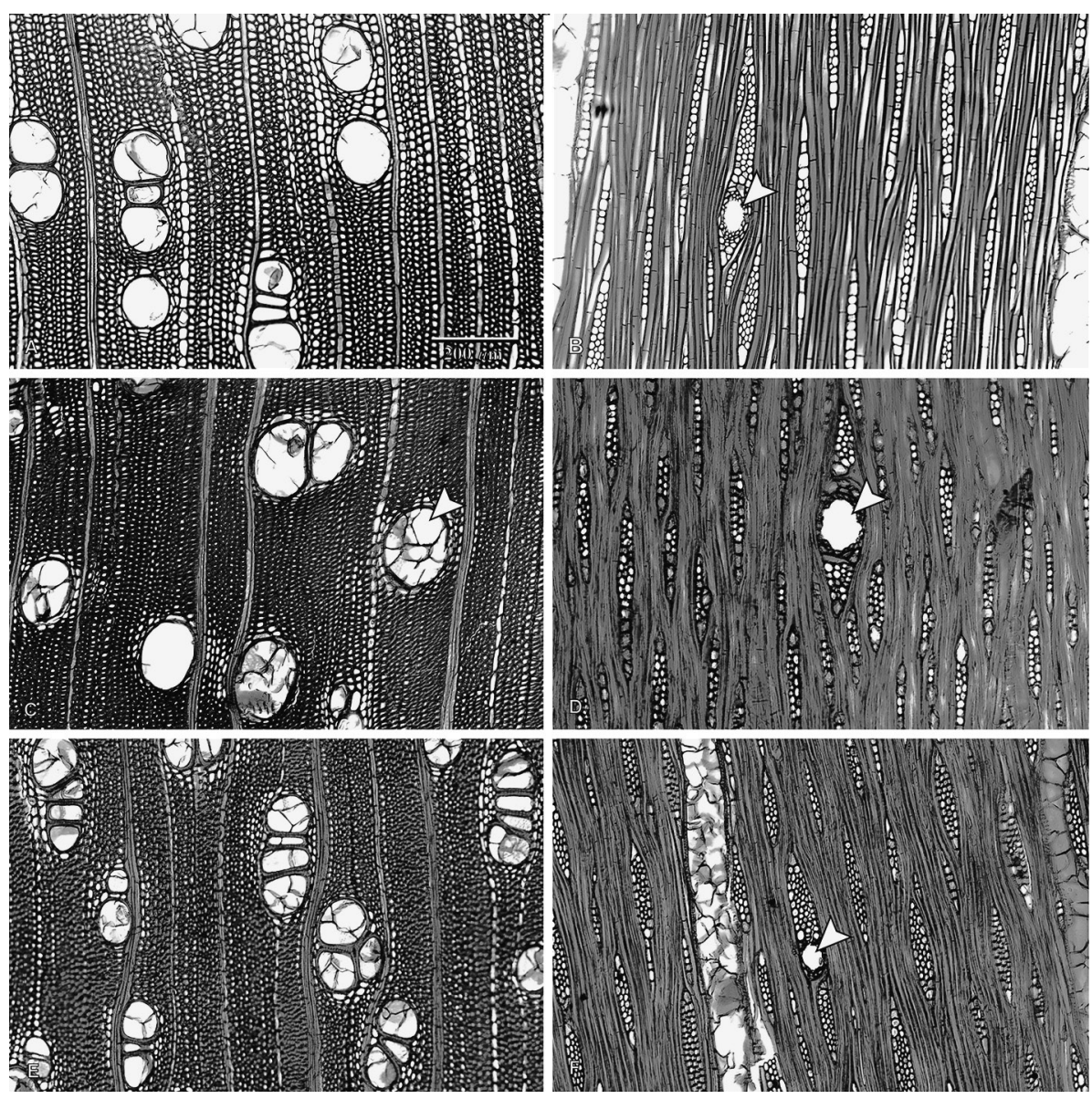

Fig. 5. Madeiras modernas Astronium-Myracrodruon-Schinopsis.

brasileira (Paula et al. 2007). Essa família inclui 70 gêneros e 875 espécies dispersas pelas regiões tropicais e subtropicais e, mais raramente, em climas temperados (Silva-Luz 2010). Segundo Forzza et al. (2010), no Cerrado de Mato Grosso ocorrem Astronium fraxinifolium Schott (gonçalo-alves), Myracrodruon urundeuva Allemão (aroeira), Schinopsis balansae Engl. e Schinopsis brasiliensis Engl. (quebracho).

Essas espécies são caducifólias, heliófitas, seletivas xerófitas ou seletivas higrófitas (Lorenzi 1992). Elas são encontradas em diversos biomas brasileiros, principalmente no Cerrado do Brasil Central (Lorenzi 1992; Rizzini 1971; Meira et al. 2007; Carmello-Guerreiro; Sartrori Paoli 2000). São características de solos rochosos e secos (aroeira, gonçalo-alves) e principalmente calcários, para quebrachos. As árvores podem atingir $12-15 \mathrm{~m}$ ou mais, como a aroeira, que pode medir até $25-30 \mathrm{~m}$ de altura, dependendo da formação onde ela ocorre (Nunes 2008; Lorenzi 1992).

As madeiras são de boa qualidade e possuem uma densidade elevada, variando de 1.09 $\mathrm{g} / \mathrm{cm}^{3}$ (gonçalo-alves) a $1.19 \mathrm{~g} / \mathrm{cm}^{3}$ (aroeira) e $1.23 \mathrm{~g} / \mathrm{cm}^{3}$ (quebracho). Elas são resistentes à deterioração natural, possuem uma longa duração e são praticamente imputrescíveis (Paula et al. 2007; Rizzini 1971, 1997; Mainieri e Chimelo 1989). Esta alta resistência é devida à elevada presença de taninos e resinas no cerne e na casca da madeira (Lorenzi 1992; Carmello-Guerreiro; Sartrori Paoli 2000; Anjos Queiroz et al. 2002). Por suas diversas qualidades, esta madeira é utilizada na construção civil, na fabricação de móveis, na carpintaria, para 
ornamentos, entre outros fins além da paisagem e da arborização em geral (Almeida et al. 1998; Lorenzi 1992).

A aroeira também possui propriedades úteis para a indústria farmacêutica (Carvalho, 1994; Carmello-Guerreiro; Sartrori Paoli 2000; Maroni 2006 et al.). A casca, as raízes e as folhas têm propriedades anti-inflamatórias, cicatrizantes, adstringentes e anti-alergênicas, e pode ser usadas no tratamento de reumatismo e úlceras (Nunes et al. 2008; Almeida et al. 1998). As folhas, depois de secas, também podem ser utilizadas como alimento para o gado (Carmello-Guerreiro; Sartrori Paoli 2000).

\section{Abordagem paleobotânica}

Segundo alguns autores (Moutarde 2006), os povos pré-históricos coletavam lenho para o combustivel, dependendo da disponibilidade de madeira perto do habitat. Não havia escolha efetuada numa espécie em particular em função das propriedades físico-químicas da madeira ou das atividades de vida cotidiana. Inversamente, para alguns outros autores os homens pré-históricos conheciam as propriedades das plantas e a escolha da madeira era realizada de acordo com as necessidades do grupo humano em função de suas atividades particulares (aquecimento, iluminação, cozinha) (Théry-Parisot 2001; Scheel-Ybert 2004).

Partindo das principais características da madeira (durabilidade, peso, densidade), várias questões podem ser levantadas. Houve uma seleção especial de madeira? Neste caso, é possível identificar os critérios associados a essa seleção e quais são eles? O tição foi coletado aleatoriamente em função de sua disponibilidade no território, próximo da área de habitação? De que maneira ele foi recolhido?

Como mencionado anteriormente, uma das características da madeira é a sua dureza e resistência. Levando em conta essas informações, várias hipóteses podem ser levantadas sobre a coleta do tição analisado. Em primeiro lugar, o galho poderia ter sido cortado, o que implicaria a utilização de um material especial e adequado. Em 2009, nas quadras 15 A-B, ao lado de onde foi encontrado o tição analisado, as escavações arqueológicas permitiram a descoberta de um machado parcialmente polido e um retocador em arenito silicificado compacto (Vialou et al. 2009). Não é impossível pensar que esse material poderia ter sido utilizado nessa ocasião. Considerando que a escavação deste nível de ocupação mais antigo, esteja ainda limitada as poucas quadras (14A-BC, AB 15-16), a ampliação das escavações talvez possa evidenciar outros vestígios associados e reforçar esta hipótese. Por outro lado, pode ser que o ramo tenha sido quebrado diretamente da árvore, o que exigiria um grande esforço físico.

Uma segunda hipótese plausível seria a coleta da madeira morta diretamente do solo. Estudos etnográficos realizados em comunidades indígenas atuais mostram que a madeira morta com disponibilidade nos arredores do habitat é o critério de seleção privilegiado pelas populações (Ramos et al. 2008).

Outro aspecto a considerar é o peso da madeira e o seu transporte até o sítio. Se a madeira é muito pesada, a possibilidade de que ela tivesse vindo de uma área distante do sítio também deve ser questionada. Os ocupantes de Ferraz Egreja percorreram vários quilômetros do lugar de coleta ao sítio arqueológico para trazer este galho ou ele foi encontrado próximo ao sítio de habitat?

Finalmente, como mencionado acima, esta madeira possui uma densidade muito alta e se consome menos rapidamente do que a madeira com menor densidade. Segundo estudos sobre as propriedades físico-químicas da madeira, os gêneros Astronium/ Myracrodruon possuem um alto poder calorífico $\left(19.067 \mathrm{~kJ} / \mathrm{kg}^{1}\right)($ Melo Júnior, dados não publicados). Na prática, isso significa que o fogo e o calor têm uma duração mais longa. Estudos sobre as populações tradicionais da Caatinga do estado do Pernambuco (município de Caruaru), nordeste do país, mostram que a escolha de espécies utilizadas como combustível é feita com base em propriedades físicas e químicas da madeira (Ramos et al. 2008).

A questão que surge então é de saber se os ocupantes do sítio tinham conhecimento dessas informações ou intuíam. Estamos diante de uma escolha, uma seleção focada nesta espécie ou em 
Um tição de aroeira em contexto arqueológico: contribuição antracológica para a compreensão da relação entre o homem e o ambiente.

R. Museu Arq. Etn., São Paulo, n. 21, p. 115-127, 2011.

suas propriedades? Se este for o caso, a ampliação das escavações desse nível de ocupação e as análises antracológicas suplementares poderiam talvez dar mais informações e confirmar a ideia de uma escolha específica de uma espécie. Em todos os casos, isso implicaria em bom conhecimento do ambiente, da vegetação e uma forte relação entre o homem e o ambiente em que vive e evolui. Isto seria especialmente verdadeiro se estas espécies tiverem sido utilizadas para fins farmacêuticos. Como mencionado anteriormente, a aroeira tem propriedades especiais e pode ser utilizadas para o tratamento de certas doenças. Infelizmente não é possível saber, neste estudo de caso, se o homem pré-histórico a utilizou para estes fins, mas a hipótese não pode ser descartada.

\section{Conclusão}

Este artigo aborda a utilização de um único recurso vegetal, um tição carbonizado, usado como combustível pelos ocupantes do sítio Ferraz Egreja, datado desses ultimos três milênios e associado a vestígios arqueológicos e a estruturas de habitação. Ele interpreta e trata essa única amostra segundo duas abordagem que fornecem informações diferentes e complementares para a interpretação e compreensão do passado.

A abordagem botânica mostra como usar os dados ecológicos atuais para poder interpretar os dados passados revelados pela análise antracológica. Quanto à abordagem paleoetnobotânica, é obtida uma série de informações importantes para entender melhor o comportamento sociocultural dos primeiros grupos ceramistas atualmente conhecidos nessa área de estudo.

Tudo isso permite a aquisição de novas informações sobre os aspectos relativos à área de coleta da matéria-prima, à seleção ou não das espécies em função do grupo e de suas atividades, da proximidade com o abrigo entre outros.

Porém, uma análise maior em termo de amostra e identificação taxonômica é necessária para que seja possível avançar no conhecimento destas relações do homem com o seu ambiante vegetal nessa região do Brasil Central.

BACHELET, C.; VIALOU, A.V.; CECCANTINI, G.; VIALOU, D. Aroeira's firebrand in an archaeological context: anthracology contribution to understanding the relationship between man and his environment. R. Museu Arq. Etn., São Paulo, n. 21, p. 115-127, 2011.

\begin{abstract}
The anthracology provides different information about use of plant resources by prehistoric Holocene populations either in the diet or in the use of raw material as a fuel for daily activities (lighting, kitchen, heat). A charred firebrand, a rarely found residue vegetal, was discovered in archaeological sediments dated to $2820 \pm 30$ years BP $(2914 \pm 40$ years cal.BP) associated with the material vestige of the first ceramic people of Mato Grosso region, in the rock shelter Ferraz Egreja (Rondonópolis, Mato Grosso). Anthracological analysis of this firebrand allowed the identification of the Aroeira tree. The ecological and paleobotanical approach of this result allowed discussing on the taxonomic identification of this sample, and the use, selection and place of procurement of this plant resource by human groups.
\end{abstract}

Keywords: Anthracology - Archaeology - Paleobotany - Charcoal - Aroeira Wood - Holocene. 


\section{Referências bibliográficas}

ALMEIDA, S.P.; PROENC̣A, C.E.B.; SANO, S.M.; RIBEIRO, J.F.

1998 Cerrado: espécies vegetais úteis. Planaltina: EMPRAPA-CEPAC.

ANJOS QUEIROZ, A.C.R.; LEMOS DE MORAIS, S.A.; NASCIMENTO, E.A.

2002 Caracterização dos taninos da aroeira-preta (Myracrodruon urundeuva). R. Árvore, 26 (4) : 485-492.

BADAL-GARCIA, E.

1992 L'anthracologie préhistorique: à propos de certains problèmes méthodologiques. Bulletin de la Société botanique Française, Actualités botaniques, 139 (2/3/4): 167-189.

BADAL-GARCIA, E.; HEINZ, C.

1991 Méthodes utilisées en anthracologie pour l'étude de sites préhistoriques. In: Waldren, W.H.; Ensenyat, J.A.; Kennard, R.C. (Eds.) II ${ }^{\text {nd }}$ Deya International Conference of Prehistory. Recent developments in Western Mediterranean prehistory: Archaeological techniques, technology and theory. v.1. British Archaeological Reports International Series, Oxford, 573:17-47.

BEAUCLAIR, M.; SCHEEL-YBERT, R.; FARACO BIANCHINI, G.; BUARQUE, A.

2009 Fire and ritual: bark hearths in SouthAmerican Tupiguarani mortuary rites. Journal of Archaeological Science, 36: 1409. 1415

CARMELLO-GUERREIRO, S.M.; SARTRORO PAOLI, A.A.

2000 Estrutura do pericarpo e da semente de Astronium graveolens Jacq. (Anacardiaceae) com notas taxonômicas. Rev. bras. Bot., 23 (1): 87-96.

CARVALHO, P.E.R.

1994 Espécies florestais brasileiras: recomendações silviculturais, potencialidades e uso da madeira. Brasília: EMBRAPA/CNPF.

CECCANTINI, G.C.T.

2002 Madeiras arqueológicas do abrigo rupestre Santa Elina. MT. Tese de Doutorado em Ciências Biológicas (Botânica). São Paulo, IB-USP.

CHABAL, L.

1992 La représentativité paléo-écologique des charbons de bois archéologiques issus du bois de feu. Bulletin de la Société botanique Française, Actualités botaniques, 139 $(2 / 3 / 4): 213-236$.
1997 Forêts et sociétés en Languedoc (Néolithique final, Antiquité tardive). L'anthracologie, méthode et paléoécologie. Documents d'archéologie française 63, Paris.

CHABAL, L.; FABRE, L.; TERRAL, J-F.; THERYPARISOT, I.

1999 L'anthracologie. In: Bourquin-Mignot, C.; Brochier, J-E.; Chabal, L. (Eds.) La botanique. Collections «Archéologiques». Paris, Editions Errance: 105-137.

COUTINHO, L.M.

2002 O bioma cerrado. In: Klein, A.L. (Org.) Eugen Warming e o cerrado brasileiro: um século depois. São Paulo, Editora UNESP: 77-93.

DESCHAMPS, R.

1979 Étude anatomique de bois d'Amérique du Sud. Volume I. Acanthaceae à Lecythidaceae. Tervuren, Musée Royal de l'Afrique Centrale.

1980 Étude anatomique de bois d'Amérique du Sud. Volume II. Leguminosae. Tervuren, Musée Royal de l'Afrique Centrale.

1985 Étude anatomique de bois d'Amérique du Sud. Volume III. Linaceae à Zygophyllaceae. Tervuren, Musée Royal de l'Afrique Centrale.

DÉTIENNE, P.; JACQUET, P.

1983 Atlas d'identification des bois de l'Amazonie et des régions voisines. Nogent-sur-Marne, Centre Technique Forestier Tropical, 640p.

FEDALTO, L.C.; MENDES, I.C.A.; CORADIN, V.T.R.

1989 Madeiras da Amazônia. Descrição do lenho de 40 espécies ocorrentes na Floresta Nacional do Tapajós. Brasília: IBAMA.

FERREIRA e SILVA, V.

2005 A exploração dos recursos litológicos na região da Cidade de Pedra, Rondonópolis-MT. Dissertação de Mestrado em Arqueologia. MAE-USP.

FIGUEIRAL, I.

1992 Méthode en anthracologie: étude de sites du Bronze final et de l'âge du Fer du nord-ouest du Portugal. Bulletin de la Société botanique Française, Actualités botaniques $139(2 / 3 / 4)$ : 167-189.

2000 A review of charcoal analysis as a tool for assessing Quaternary and Tertiary environments: achievements and limits. Palaeogeography, Palaeoclimatology, Palaeoecology, 164: 397-407. 
Um tição de aroeira em contexto arqueológico: contribuição antracológica para a compreensão da relação entre o homem e o ambiente.

R. Museu Arq. Etn., São Paulo, n. 21, p. 115-127, 2011.

FORZZA, R.C.; LEITMAN, P.M.; COSTA, A.F.; CARVALHO JR., A.A.; PEIXOTO, A.L.; WALTER, B.M.T.; BICUDO, C.; ZAPPI, D.; COSTA, D.P.; LLERAS, E.; MARTINELLI, G.; LIMA, H.C.; PRADO, J.; STEHMANN, J.R.; BAUMGRATZ, J.F.A.; PIRANI, J.R.; SYLVESTRE, L.; MAIA, L.C.; LOHMANN, L.G.; QUEIROZ, L.P.; SILVEIRA, M.; COELHO, M.N.; MAMEDE, M.C.; BASTOS, M.N.C.; MORIM, M.P.; BARBOSA, M.R.; MENEZES, M.; HOPKINS, M.; SECCO, R.; CAVALCANTI, T.B.; SOUZA, V.C.

2010 Lista de Espécies da Flora do Brasil. Jardim Botânico do Rio de Janeiro. http:// floradobrasil.jbrj.gov.br

FREIRE, G.Q.

2011 Caracterização da flora lenhosa de Lagoa Santa, MG, dos últimos 10.000 anos através da anatomia de lenhos sub-fósseis. Doutorado em Ciências Biológicas (Botânica). São Paulo, IB-USP.

HEINZ, C.

1990 Dynamique des végétations Holocènes en Méditerranée nord occidentale d'après l'anthracoanalyse de sites préhistoriques: méthodologie et paléoécologie. Paléobiologie Continentale, 16 (2):1-212.

HESS, R.W.

1946 Keys to American woods. Tropical Woods, 85: 11-19.

1948 Keys to American woods. Tropical Woods, 94: 29-52.

IAWA COMMITTEE

1964 Multilingual glossary of terms used in wood anatomy. Committee on nomenclature, International Association of Wood Anatomists.

1989 IAWA list of microscropic features for hardwood identification. IAWA Journal, 10: 219-332.

LORENZI, H.

1992 Árvores Brasileiras: Manual de identificação e cultivo de plantas arbóreas nativas do Brasil. Nova Odessa, SP: Instituto Plantarum.

MAINIERI, C.; CHIMELO, J.P.

1989 Fichas de características das madeiras brasileiras. São Paulo, IPT.

MARONI, C.B.; DI STASI, L.C.; MACHADO, S.R.

2006 Plantas medicinais do cerrado do Botucatu. Guia ilustrado. São Paulo: Editora UNESP.

MEIRA, W.R.; CARON, B.O.; SCHMIDT, D.; SANTOS FILHO, B.G.; MEDEIROS, S. L.P.; MANFRON, P.A.; MÜLLER, L.

2007 Ocorrência e identificação da Aroeira vermelha no estado de Rondônia, Amazô- nia ocidental. Revista da FZVA Uruguaiana, 14 (2): 54-68.

MOUTARDE, F.

2006 L'évolution du couvert ligneux et de son exploitation par l'homme dans la vallée du Lurín (côte centrale du Pérou), de l'Horizon Ancien (900-100 av.J.C.) à l'Horizon Tardif (1460-1532 ap. J.-C.). Approche anthracologique. Thése de doctorat. Université Paris I.

NUNES, Y.R.F.; FAGUNDES, M.; ALMEIDA, H.S.; MAGALHÃES VELOSO, M.D.

2008 Aspectos ecológicos da aroeira (Myracrodruon urundeuva Allemão-Anacardiaceae): fenologia e germinação de sementes. Rev. Árvore, 32 (2): 233-243.

PAULA, J.E.; HAMBURGO ALVES, J.L.

2007897 madeiras nativas do Brasil, anatomia, dendrologia, dendrometria, produção, uso. Porto Alegre: Cinco Continentes.

RAMOS, A.R.; MEDEIROS, P.M.; ALMEIDA, A.L.S.; FELICIANO, A.L.P.; ALBUQUERQUE, U.P.

2008 Can wood quality justify local preferences for firewood in an area of caatinga (dryland) vegetation? Biomass and Bioenergy, 32: 503-509.

RATTER, J.A; BRIDGEWATTER, S.; RIBEIRO, J.F.

2003 Analysis of floristic composition of the Brazilian cerrado vegetation III: comparison of the woody vegetation of 376 areas. Edinburgh Journal of Botany, Edinburgh, 60 (1): 57-109.

RECORD, S.J.

1942 Keys to American woods. Tropical Woods, 72: 19-35.

1943a Keys to American woods. Tropical Woods, 73: 23-42.

$1943 b$ Keys to American woods. Tropical Woods, 75: 8-26.

1944a Keys to American woods. Tropical Woods 76: 32-47.

RIBEIRO, J.F.; WALTER, M.T.B.

2008 As principais fitofisionomias do bioma cerrado. In: Matiko Sano, S.; Pedrosa de Almeida, S.; Ribeiro, J.F. (Eds.) Cerrado. Ecologia e flora. Embrapa cerrados. Brasília, DF, Embrapa Informação Tecnológica: 153-212.

RIZZINI, C.T.

1971 Árvores e madeiras úteis do Brasil. Manual de dendrologia brasileira. São Paulo: Edgard Blücher.

1997 Tratado de fitogeografia do Brasil : aspectos ecológicos, sociólogicos e florísticos. Rio de Janeiro: Âmbito Cultural Edições Ltda. 
SANTIN, D.A

1989 Revisão taxômica do gênero Astronium Jacq. Revalidação do gênero Myracrodruon Fr. (Anacardiaceae). Dissertação de Mestrado. Campinas, IB-Unicamp.

SANTIN, D.A.; LEITÃO-FILHO, H.F.

1991 Restabelecimento e revisão taxonômica do gênero Myracrodruon Freire Allemão (Anacardiaceae). Revista Brasileira de Botânica, 14: 133-145.

SCHEEL-YBERT, R.

1998 Stabilité de l'Ecosystème sur le Littoral Sud-est du Brésil à l'Holocène Supérieur (5500-1400 ans BP). Les Pêcheurs-Cueilleurs-Chasseurs et le Milieu Végétal: Apports de l'Anthracologie. Thèse de doctorat, Université Montpellier II, 3 volumes.

2001 Man and vegetation in Southeastern Brazil during the Late Holocene. Journal of Archaeological Science, 28: 471-480.

2004 Teoria e métodos em antracologia. 2. Técnicas de campo e de laboratório. Arquivos do Museu Nacional, Rio de Janeiro, 62 (4): 343-356.

SILVA-LUZ, C.L.; PIRANI, J.R.

2010 Lista de espécies da flora do Brasil: Anacardiaceae. Rio de Janeiro: Jardim Botânico do

THÉRY-PARISOT, I. Rio de Janeiro (Página na Rede Mundial).

2001 Economie des combustibles an Paléolithique.
CEPAM. Dossier de Documentation Archéologique $n^{\circ} 20$, CNRS éditions, Paris.

VILHENA VIALOU, A.; BLASIS, P.A.D; FIGUTI, L;; PAILLET, P.; VIALOU, D.

1999 Art rupestre et habitats préhistoriques au Mato Grosso (Brésil). L’Amérique du sud: des chasseurs-cueilleurs à l'Empire Inca. BAR International series, 746: 9-21.

VILHENA VIALOU, A. (Ed.)

2006 Pré-história do Mato Grosso. 2. Cidade de Pedra. São Paulo: Edusp.

2009 Tecnologia lítica no planalto brasileiro: persistência ou mudança. Revista de Arqueologia, 22 (2): 35-53.

VILHENA VIALOU, A.; VIALOU, D.

1994 Les premiers peuplements préhistoriques du Mato Grosso. Bulletin de la Société Préhistorique Française, 91: 257-263.

VIALOU, D.; VILHENA VIALOU, A.; FIGUTI, L. (Org.)

2009 L'Homme fossile et ses paléoenvironnements dans le bassin du Paraná - Brésil. Rapport de mission de recherches. Ministère des Affaires Etrangères et Européennes, Paris, $59 \mathrm{p}$.

2010 L'Homme fossile et ses paléoenvironnements dans le bassin du Paraná - Brésil. Rapport de mission de recherches. Ministère des Affaires Etrangères et Européennes, Paris, $55 \mathrm{p}$.

\section{Banco de dados:}

Insidewood

http://insidewood.lib.ncsu.edu/search.23 
